\title{
An observational study of once-daily modified-release methylphenidate in ADHD: quality of life, satisfaction with treatment and adherence
}

\author{
Aribert Rothenberger • Andreas Becker • \\ Dieter Breuer • Manfred Döpfner
}

Published online: 8 September 2011

(C) The Author(s) 2011. This article is published with open access at Springerlink.com

\begin{abstract}
Attention deficit hyperactivity disorder (ADHD) impacts significantly on the quality of life $(\mathrm{QoL})$ of patients and their families. Choice of therapy is increasingly influenced by treatment satisfaction and patient preference, with once-daily modified-release methylphenidate (MPH-MR) formulations offering clear benefits compared with immediate-release (IR) dosage forms. The effects of MPH-MR on QoL in ADHD have not been widely investigated and need more clarity in practice. The open-label OBSEER study evaluated the effectiveness and tolerability of Equasym $\mathrm{XL}^{\circledR}$, a MPH-MR formulation, in routine practice. Children and adolescents (aged 6-17 years) with ADHD and attending school were included if Equasym $\mathrm{XL}^{\circledR}$ treatment was planned by the treating physician. Physicians, parents and patients completed questionnaires assessing QoL (KINDL; parent, child or adolescent versions), satisfaction with medication, adherence and treatment tolerability at baseline (Visit 1), 1-3 weeks (Visit 2) and 6-12 weeks (Visit 3) over a maximum 3-month observation period. Data from 822 consecutively referred patients were analysed. QoL and medication satisfaction increased from Visit 1 to Visit 3, with both patients and parents rating therapy with Equasym $\mathrm{XL}^{\circledR}$ as better than previous drug therapy. KINDL total score effect sizes were 0.67 (parents' ratings), 0.52
\end{abstract}

A. Rothenberger and A. Becker contributed equally to the paper.

\footnotetext{
A. Rothenberger $(\square) \cdot$ A. Becker

Department of Child and Adolescent Psychiatry,

University of Göttingen, Von-Siebold-Str. 5,

37075 Göttingen, Germany

e-mail: arothen@gwdg.de

D. Breuer · M. Döpfner

Department of Child and Adolescent Psychiatry,

University of Cologne, Cologne, Germany
}

(children's ratings) and 0.51 (adolescents' ratings; all $p<0.001)$. All KINDL subscores also increased: both parents and patients had the greatest improvement for school. Adherence to Equasym $\mathrm{XL}^{\circledR}$ was frequently rated as superior to prior treatment, particularly compared with MPH-IR repeated dosing. Treatment was generally well tolerated; approximately $3 \%$ of the patients discontinued treatment due to adverse events. Equasym $\mathrm{XL}^{\circledR}$ improved QoL compared with prior therapy, and resulted in good medication satisfaction and adherence in drug-naïve and previously treated patients.

Keywords Quality of life - KINDL questionnaire · Satisfaction - Methylphenidate · ADHD · Adherence

\section{Introduction}

Quality of life (QoL) has become an increasingly important outcome in child mental health clinical research [10, 11, 14], and it has long been recognised that a diagnosis of attention deficit hyperactivity disorder (ADHD) can result in broad impairments of QoL in patients and their families $[24,26]$. QoL in ADHD is influenced by numerous factors [35], including physical, psychological, cognitive and social aspects of wellbeing and function [14].

ADHD can have a significant impact on a patient's perception of their QoL. Everyday activities such as school and homework, family routines and playing with other children may be affected, as well as relationships with family members and peers [12]. QoL in patients with ADHD has been shown to be considerably lower than community norms [34], and studies show that patients with ADHD experience QoL deficits comparable with those in other chronic diseases, such as asthma, cancer and cerebral 
palsy [17, 38]. ADHD has also been shown to impact negatively on parents' QoL and emotional health, and presents a burden on the family as a whole [12]. Difficulties that families of children with ADHD may experience include strained family relationships, parenting distress and worry, depression, higher incidences of divorce and separation, and possible effects on work status and productivity $[12,22]$.

Improvement of patient QoL is regarded as an important treatment goal [7]. It is thought that treatments that can provide effective symptom control in ADHD may also have the potential to improve patients' overall QoL [4]. Methylphenidate (MPH) is recognised as the first-line choice of medication for reducing ADHD symptoms in children and adolescents [4]. However, the effect of MPH treatment on the everyday functioning and wellbeing of children and adolescents with ADHD has not been well studied to date. An open-label study showed that QoL scores improved along with symptoms during 3-month MPH therapy, suggesting that such effects could be secondary to effects on the core features of ADHD [21]. Consistent with this, a study that had an open-label dose optimisation phase followed by a randomised, placebocontrolled, double-blind classroom phase demonstrated that MPH therapy was associated with a robust improvement in child and family health-related QoL [27]. Further analyses of the study showed that the improvement in QoL was linked to improvements in both ADHD symptoms and medication satisfaction, with patient satisfaction as a strong predictor of initial changes in QoL as symptom improvement [18]. There is also some evidence from this and another study that family QoL measures are improved by MPH treatment [7, 18]. The development of specialised tools (for example the Global Impression of Perceived Difficulties [GIPD] scale, the Life Participation Scale [LPS] and the Kinder Lebensqualitätsfragebogen [KINDL] questionnaire [31, 37, 39]) allows the opportunity to measure the QoL of children and adolescents with ADHD, and their response to treatment, comprehensively.

Treatment satisfaction and patient/parent preference are increasingly important determinants of the success of clinical care in ADHD [20]. Improved patient satisfaction may result in better outcomes through greater adherence to therapy [8]. Parents are often asked how satisfied they are with ADHD medication in clinical trials [5], and generally show higher rates of satisfaction than their children, particularly in the treatment of ADHD [16]. Multiple dosing can be problematic, as it can cause adherence issues and complications related to privacy, stigmatisation by classmates, potential abuse and accountability of the school administration [23]. By eliminating the need for multiple daily dosing, the introduction of once-daily, long-acting medication has improved the convenience of ADHD treatment, with potential for greater satisfaction for both patients and their parents.

The OBSEER (OBservation of Safety and Effectiveness of Equasym XL ${ }^{\circledR}$ in Routine care) study was an observational, non-controlled, non-interventional, post-marketing surveillance study conducted in Germany, which examined changes in effectiveness and safety outcomes over 3 months in patients with ADHD receiving once-daily Equasym $\mathrm{XL}^{\circledR 1}$ (Shire Pharmaceuticals Ireland Limited, Ireland) [15]. In this paper, we present a longitudinal assessment of QoL and medication satisfaction, including adherence and tolerability, in patients enrolled in the OBSEER study.

\section{Methods}

Study design

The open-label, prospective, multicentre, observational, post-marketing OBSEER study was designed primarily to assess the effectiveness and safety, and is described in full elsewhere [15]. Here, pre-specified outcomes related to QoL and satisfaction with therapy are examined.

\section{Patients and treatment}

Patients with ADHD (diagnosed according to the Diagnostic and Statistical Manual of Mental Disorders, Fourth Edition, Text Revision [DSM]-IV-TR [2] or the International Classification of Diseases [ICD]-10 criteria [40]) aged 6-17 years and attending school were included if treatment with Equasym XL ${ }^{\circledR}$ was planned by the treating physician. Patients were included whether or not they had received Equasym $\mathrm{XL}^{\circledR}$ or other treatment prior to the study.

Treatment with once-daily Equasym $\mathrm{XL}^{\circledR}$ was administered according to standard practice under the therapeutic responsibility of the attending physician; ethics or institutional review board approval was not required for this study. Written informed consent was obtained from parents.

\section{Assessments}

\section{Health-related QoL}

QoL was assessed using the KINDL questionnaire for the assessment of health-related QoL in childhood and

\footnotetext{
${ }^{1}$ Equasym XL is the UK trade name, and is registered and marketed by Shire in the following countries under the following trademarks: Denmark, Equasym Depot; Finland, Equasym Retard; France, Quasym LP; Germany, Equasym Retard; Ireland, Equasym XL; Netherlands, Equasym XL; Norway, Equasym Depot; Sweden, Equasym Depot; South Korea, Metadate CD; Mexico, Metadate CD. Information correct at August 2011.
} 
adolescence [31]. This is a short, validated tool comprising 24 items, with six subscores (physical wellbeing, emotional wellbeing, self-esteem, family, friends and school). Three different versions were used according to the age group: KID-KINDL was used for children aged 6-11 years old; the self-reported KIDDO-KINDL for adolescents aged 12-17 years old; and KINDL for parents of patients aged 6-17 years old. Scores were transformed such that the range of possible values for the sub-scores and the total score was from 0 (most negative state) to 100 (most positive state).

\section{Treatment satisfaction}

Treatment satisfaction was evaluated using the Satisfaction with Medication scale (SAMS), a newly designed tool that consists of 12 items (including an item for global satisfaction with medication) scored on a six-point scale, with low values indicating positive attitudes to drug therapy, and high values indicating negative attitudes. The parent report form of the SAMS (SAMS-P) assessed parents' satisfaction with medication, while the self-report form (SAMS-S) assessed patient satisfaction with medication. The total score of each rating scale is the sum of the item divided by the number of items, and ranged from 1 to 6 . The development of the SAMS tool is described in a companion paper [20].

\section{Physician-rated adherence and tolerability}

Adherence to treatment was graded on a scale between 1 and 6 (where $1=$ excellent [very good] and $6=$ failed [inadequate]) by the treating physician. Treatment tolerability was assessed by the treating physician as 'very good', 'good', 'moderate' and or 'poor'.

\section{Assessment timings}

The planned observation period for each patient was 6-12 weeks after first use of Equasym $\mathrm{XL}^{\circledR}$. Three visits were planned: Visit 1, baseline visit and initiation of Equasym XL ${ }^{\circledR}$ treatment; Visit 2, follow-up visit scheduled for 1-3 weeks after first use of Equasym $\mathrm{XL}^{\circledR}$; Visit 3, final visit 6-12 weeks after first use of Equasym $\mathrm{XL}^{\circledR}$. The attending physician assessed adherence at each visit, and global tolerability at Visit 3. Patients and parents assessed satisfaction with medication at each visit, and QoL at Visit 1 and Visit 3.

\section{Statistical analyses}

The following outcomes were assessed: parent-rated satisfaction with therapy and perception of patient's QoL by visit and as change from baseline; patient-rated satisfaction with therapy and QoL by visit and as change from baseline; physician-rated tolerability and adherence.

Results presented are for the intent-to-treat population. All statistical analyses were performed post-hoc. Paired $t$ tests were used for the analyses of KINDL scores, and multivariate analysis of variance for the analyses of SAMS scores; effect sizes $[28,36]$ were calculated using Cohen's $d$ [13]. In subgroup analyses, patients were assigned to groups according to their treatment prior to starting Equasym XL ${ }^{\circledR}$ (no treatment; or treatment with MPH modified release (MR), MPH immediate release (IR) administered once daily, MPH-IR administered several times per day, or 'other', where treatment was unspecified (atomoxetine, amphetamine or insufficiently specified).

\section{Results}

\section{Study population}

In total, 852 patients were registered for the study. Thirty patients were excluded from the analysis due to invalid data; therefore, 822 patients were included in the safety analysis population. Baseline demographics for the total population are described elsewhere [15].

Six hundred and fourteen patients had received prior treatment for ADHD, while 208 patients were treatmentnaïve; baseline characteristics by prior treatment group are shown in Table 1. The mean (standard deviation [SD]) timing for Visit 3 was 10.1 (4.0) weeks after the first use of Equasym $\mathrm{XL}^{\circledR}$.

\section{Health-related quality of life}

On an average, the parent-rated KINDL total score was 62.8 points at Visit 1 and 71.1 points at Visit 3, indicating a 13.3\% improvement in $\mathrm{QoL}$ on treatment with Equasym $\mathrm{XL}^{\circledR}$, which was significant $(p<0.001$; Table 2$)$. Descriptively, the greatest improvement was for the sub-score school, which increased by 11.1 points, and the smallest improvement was for the sub-score physical wellbeing, which increased by 6.9 points. Similarly, the patient-rated KIDKINDL (6-11 years) total score averaged 66.3 points at Visit 1 and 73.4 points at Visit 3, indicating an improvement in QoL across all subscales with Equasym $\mathrm{XL}^{\circledR}$ which was significant $(p<0.001$; Table 2$)$. The greatest improvement in the KID-KINDL was for school, which increased by 11.1 points, while the smallest improvement was for physical wellbeing, which increased by 4.9 points. Effect sizes of parent ratings (Cohen's $d=0.37-0.67$ ) and patient ratings (Cohen's $d=0.22-0.54$ ) were all in the small-to-moderate range (Table 2). 
Table 1 Baseline demographics and disease characteristics by prior treatment

\begin{tabular}{|c|c|c|c|c|c|c|}
\hline & $N$ & None & $\begin{array}{l}\text { MPH-IR } \\
\text { once-daily }\end{array}$ & MPH-IR repeated & MPH-MR & $\begin{array}{l}\text { Other, no } \\
\text { specification }\end{array}$ \\
\hline \multicolumn{7}{|l|}{ Baseline demographics $(n=822)$} \\
\hline Patients, $n(\%)$ & 822 & $208(25.30)$ & $101(12.29)$ & $270(32.84)$ & $203(24.70)$ & $40(4.87)$ \\
\hline Male, $n(\%)$ & 663 & $167(25.19)$ & $80(12.07)$ & $217(32.73)$ & $166(25.04)$ & $33(4.98)$ \\
\hline Mean (SD) age (years) & 808 & $9.76(2.74)$ & $9.78(2.25)$ & $9.94(2.40)$ & $10.46(2.29)$ & $10.61(2.60)$ \\
\hline Mean (SD) height (cm) & 764 & $143.15(15.62)$ & $143.30(14.77)$ & $142.81(14.52)$ & $145.73(15.58)$ & $144.22(14.51)$ \\
\hline Mean (SD) weight (kg) & 786 & $38.32(14.82)$ & $37.34(12.28)$ & $37.79(13.90)$ & $38.37(12.85)$ & $37.10(12.34)$ \\
\hline Mean (SD) BMI $\left(\mathrm{kg} / \mathrm{m}^{2}\right)$ & 758 & $18.13(3.56)$ & $17.74(3.13)$ & $18.01(3.62)$ & $17.71(3.17)$ & 17.47 (3.04) \\
\hline \multicolumn{7}{|l|}{ ADHD diagnosis $(n=778)$} \\
\hline F90.0: disturbance of activity/attention, $n(\%)$ & 431 & $100(52.08)$ & $47(52.22)$ & $152(57.58)$ & $116(58.88)$ & $16(45.71)$ \\
\hline F90.1: hyperkinetic conduct disorder, $n(\%)$ & 283 & $69(35.94)$ & $32(35.56)$ & $94(35.61)$ & $71(36.04)$ & $17(48.57)$ \\
\hline F90.8: other hyperkinetic disorders, $n(\%)$ & 64 & $23(11.98)$ & $11(12.22)$ & $18(6.82)$ & $10(5.08)$ & $2(5.71)$ \\
\hline
\end{tabular}

$B M I$ body mass index, $I R$ immediate release, $M R$ modified release, $M P H$ methylphenidate, $S D$ standard deviation

Table 2 Summary of analysis of KINDL quality of life scores (on three different versions of the questionnaire) for patients and their parents

\begin{tabular}{|c|c|c|c|c|c|}
\hline \multirow[t]{2}{*}{ Quality of life rating scale } & \multirow[t]{2}{*}{$N$} & \multicolumn{2}{|c|}{ Assessment visit } & \multicolumn{2}{|c|}{ Main effect $t$ test and effect size } \\
\hline & & $\begin{array}{l}\text { Visit } 1 \\
\text { Mean (SD) }\end{array}$ & $\begin{array}{l}\text { Visit } 3 \\
\text { Mean (SD) }\end{array}$ & $t^{*}$ & Cohen's $d$ (Visit 1-Visit 3) \\
\hline \multicolumn{6}{|l|}{ Parent ratings (KINDL-P) } \\
\hline Total score & 590 & $62.75(13.34)$ & $71.10(11.71)$ & -16.3 & 0.67 \\
\hline Physical wellbeing & 600 & $71.83(18.25)$ & $78.77(16.35)$ & -9.1 & 0.37 \\
\hline Emotional wellbeing & 600 & $67.55(17.52)$ & $74.77(15.08)$ & -10.3 & 0.42 \\
\hline Self esteem & 600 & $54.94(18.26)$ & $63.50(16.26)$ & -11.6 & 0.47 \\
\hline Family & 600 & $62.06(19.42)$ & $69.42(16.90)$ & -10.2 & 0.42 \\
\hline Friends & 600 & $60.19(20.99)$ & $68.74(17.85)$ & -11.3 & 0.46 \\
\hline School & 590 & $60.67(18.56)$ & $71.81(16.28)$ & -14.4 & 0.59 \\
\hline \multicolumn{6}{|c|}{ Patient ratings (age 6-11 years, KID-KINDL) } \\
\hline Total score & 438 & $66.28(13.37)$ & $73.38(11.66)$ & -10.9 & 0.52 \\
\hline Physical wellbeing & 445 & $74.08(17.15)$ & $78.93(16.44)$ & -5.4 & 0.26 \\
\hline Emotional wellbeing & 445 & $71.66(16.77)$ & $77.02(14.68)$ & -6.4 & 0.30 \\
\hline Self esteem & 445 & $58.10(20.11)$ & $65.88(19.88)$ & -7.4 & 0.35 \\
\hline Family & 444 & $67.43(20.12)$ & $75.02(16.05)$ & -8.3 & 0.39 \\
\hline Friends & 444 & $66.85(21.49)$ & $73.02(18.91)$ & -6.3 & 0.30 \\
\hline School & 440 & $59.15(22.01)$ & $70.24(18.06)$ & -10.2 & 0.48 \\
\hline \multicolumn{6}{|c|}{ Patient ratings (age 12-17 years, KIDDO-KINDL) } \\
\hline Total score & 152 & $65.63(12.88)$ & $71.69(12.20)$ & -6.2 & 0.51 \\
\hline Physical wellbeing & 154 & $72.81(17.54)$ & $77.68(16.45)$ & -3.4 & 0.28 \\
\hline Emotional wellbeing & 154 & $72.40(16.18)$ & $76.18(14.85)$ & -2.8 & 0.22 \\
\hline Self esteem & 154 & $57.36(18.78)$ & $64.77(18.90)$ & -5.1 & 0.41 \\
\hline Family & 154 & $66.25(23.18)$ & $73.17(19.05)$ & -4.2 & 0.34 \\
\hline Friends & 154 & $68.14(19.99)$ & $72.63(17.41)$ & -3.2 & 0.25 \\
\hline School & 152 & $55.98(16.45)$ & $65.21(16.33)$ & -6.7 & 0.54 \\
\hline
\end{tabular}

Cohen's $d$ effect sizes are considered small $(0.20 \geq d<0.50)$, medium $(0.50 \geq d<0.80)$ or large $(0.80 \geq d)$ [13]

$S D$ standard deviation

* All effects are statistically significant at $p<0.001$ 


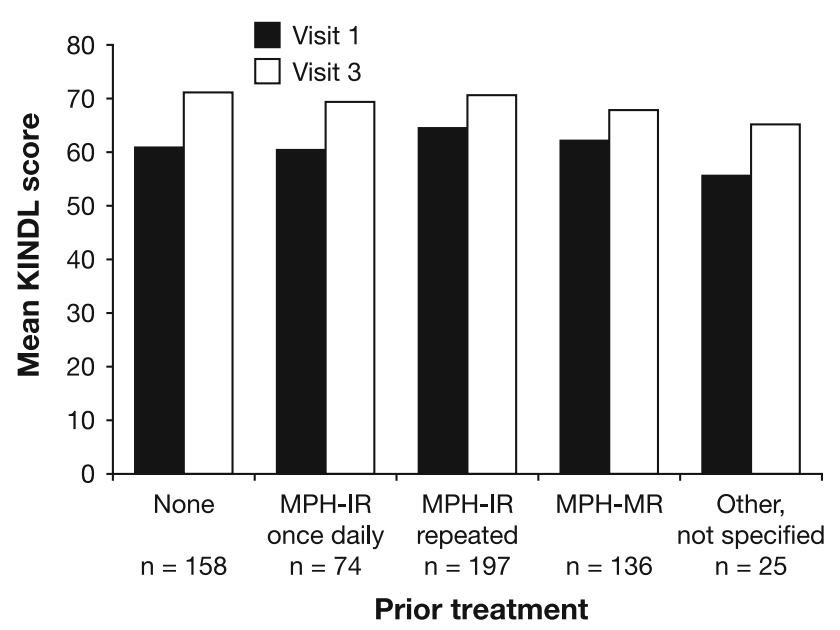

Fig. 1 Quality of life total scores (KINDL questionnaire, parent ratings) during the study, by prior treatment. All comparisons are significant at $p \leq 0.001$ (two-tailed test between KINDL total score at Visit 1 versus total score at Visit 3). IR immediate release, $M P H$ methylphenidate, $M R$ modified release

There were no substantial differences between the results of the KID-KINDL questionnaire and the KIDDOKINDL (12-17 years) version for the total score $(t=0.350 ; p=0.726)$ and all other scores (Table 2). The KIDDO-KINDL total score averaged 65.6 at Visit 1 and 71.7 at Visit 3, which was a significant improvement $(p<0.001$; Table 2). In analyses by prior treatment, improvements were found in all subgroups, with the largest effects for both parents' and patients' ratings seen in the group with no prior pharmacotherapy (Fig. 1).

\section{Treatment satisfaction}

For patients with at least one post-baseline visit, both parent- and patient-rated SAMS scores decreased from Visit 1 to the last visit (Visit 2 or Visit 3), indicating an improvement in satisfaction on medication with Equasym $\mathrm{XL}^{\circledR}$ compared with previous drug therapy (Table 3). Mean (SD) scores decreased from 2.8 (1.1) to 2.4 (1.1) points for parent ratings, and from 2.6 (1.0) to 2.3 (1.0) points for patient ratings. Thus, both patients and their parents rated therapy with Equasym $\mathrm{XL}^{\circledR}$ as better than the previous drug therapy.

Subgroup analyses by prior treatment showed that the smallest improvement in patient satisfaction was found for the group of patients who had been previously treated with MPH-MR (difference in scores -0.13) and the greatest improvement was in the 'other' subgroup (difference in scores -0.70). By parental assessment, improvements over previous MPH treatment were similar for MPH-MR, oncedaily MPH-IR and MPH-IR administered several times a day $(-0.34,-0.33$ and -0.39 , respectively) and greatest for the 'Other' subgroup $(-0.85)$.

Physician-rated adherence

The mean (SD) adherence score improved from 2.1 (1.2) to 1.5 (1.0) during the study, with the majority of patients rated by their physician as 'very good' or 'good' at last visit (Fig. 2a). Adherence during Equasym XL ${ }^{\circledR}$ treatment was frequently rated as superior to adherence during prior treatment (Fig. 2b). A particular advantage was noted for Equasym XL ${ }^{\circledR}$ versus MPH-IR administered several times per day, with $57.7 \%$ of the patients rated as having better adherence with Equasym $X^{\circledR}{ }^{\circledR}$.

\section{Physician-rated tolerability}

Adverse events are reported elsewhere [15]. Treatment with Equasym $\mathrm{XL}^{\circledR}$ was generally well tolerated; a total of $26 / 822$ evaluable patients $(3.2 \%)$ discontinued treatment due to adverse events.

At Visit 3, physicians rated the global tolerability of Equasym $\mathrm{XL}^{\circledR}$ as 'very good' in the majority (415/734; $56.5 \%$ ) of the patients. 'Good' was the next most frequent tolerability rating, for 270/734 (36.8\%) patients, with only 33/734 (4.5\%) patients rated as having 'moderate' tolerability and 16/734 (2.2\%) patients as 'poor' (no assessment was provided for 88 patients). When analysed by prior treatment, the main differences were seen in the categories 'very good' and 'good' (Fig. 3). Patients who were treated with MPH-MR prior to the

Table 3 Summary of analysis of satisfaction with medication scale scores for patients and their parents

\begin{tabular}{|c|c|c|c|c|c|c|c|c|c|}
\hline \multirow[t]{3}{*}{ Satisfaction with medication } & \multirow[t]{3}{*}{$N$} & \multicolumn{6}{|c|}{ Assessment visit } & \multicolumn{2}{|c|}{ Main effect MANOVA and effect size } \\
\hline & & \multicolumn{2}{|c|}{ Visit 1} & \multicolumn{2}{|c|}{ Visit 2} & \multicolumn{2}{|c|}{ Visit 3} & \multirow[t]{2}{*}{$\mathrm{F}(\mathrm{t})^{*}$} & \multirow[t]{2}{*}{ Cohen's $d$ (Visit 1-Visit 3) } \\
\hline & & Mean & SD & Mean & SD & Mean & SD & & \\
\hline Parent rating & 484 & 2.80 & 1.07 & 2.55 & 1.04 & 2.41 & 1.07 & 23.2 & 0.31 \\
\hline Patient rating & 468 & 2.59 & 0.96 & 2.34 & 0.96 & 2.27 & 0.98 & 22.5 & 0.38 \\
\hline
\end{tabular}

ANOVA analysis of variance; $S D$ standard deviation

* All effects are statistically significant at $p<0.001$ 
(a)

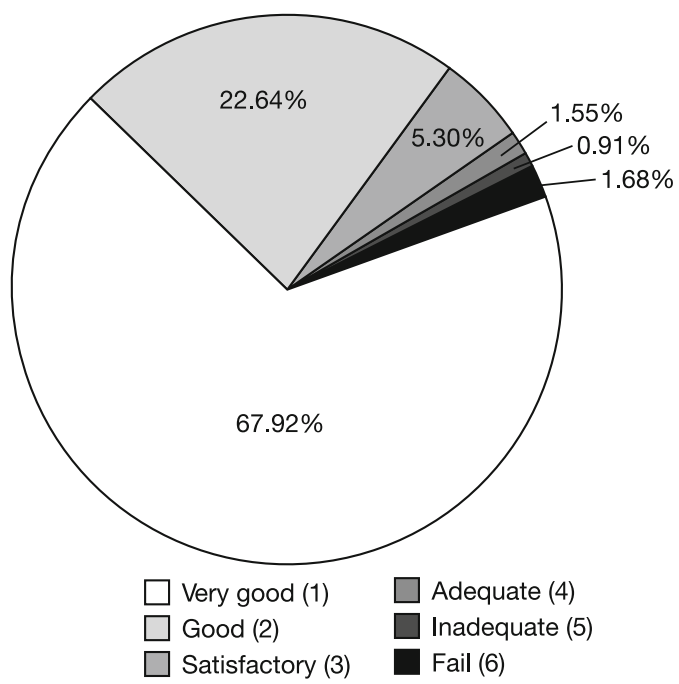

(b) 100

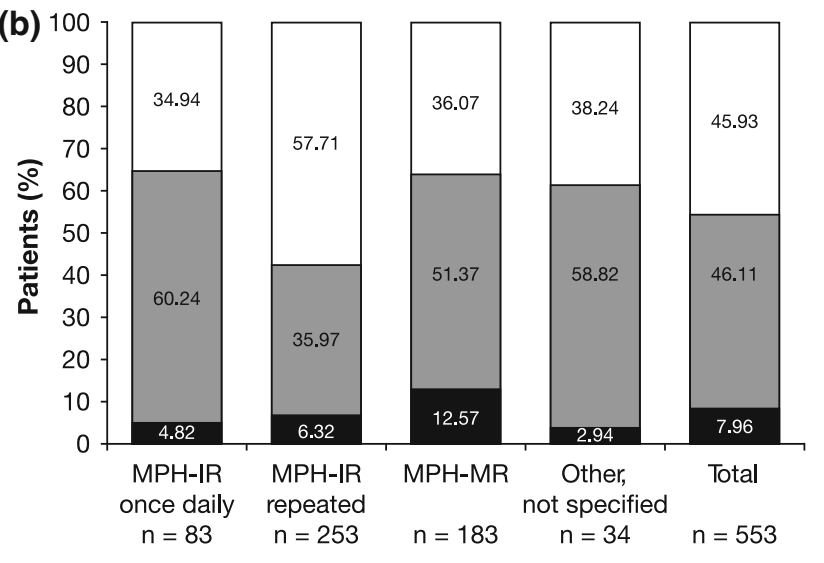

Prior treatment

$\square$ Better adherence to $\quad \begin{aligned} & \text { Better adherence to } \\ & \text { Equasym } X L^{\circledR}\end{aligned}$
$\square$ prior treatment
Equal adherence to
Equasym $X L^{\circledR}$ and
prior treatment

Fig. 2 a Mean ratings of adherence to treatment with Equasym $\mathrm{XL}^{\circledR}$, as assessed by attending physicians, at last visit. $n=773$; 49 missing values. 1 very good, 6 fail. $\mathbf{b}$ Adherence to treatment with Equasym $\mathrm{XL}^{\circledR}$ compared with adherence to prior treatment. $n=553 ; 61$ missing values. $I R$ immediate release, $M P H$ methylphenidate, $M R$ modified release

study showed the highest ratings for the categories 'moderate' and 'poor'.

\section{Discussion}

We report that patients with ADHD showed improvements in QoL and satisfaction with medication during treatment with once-daily Equasym $\mathrm{XL}^{\circledR}$ in this large observational study. Improvements were similar for both parent- and patient-assessed outcomes. There were no signs that patient

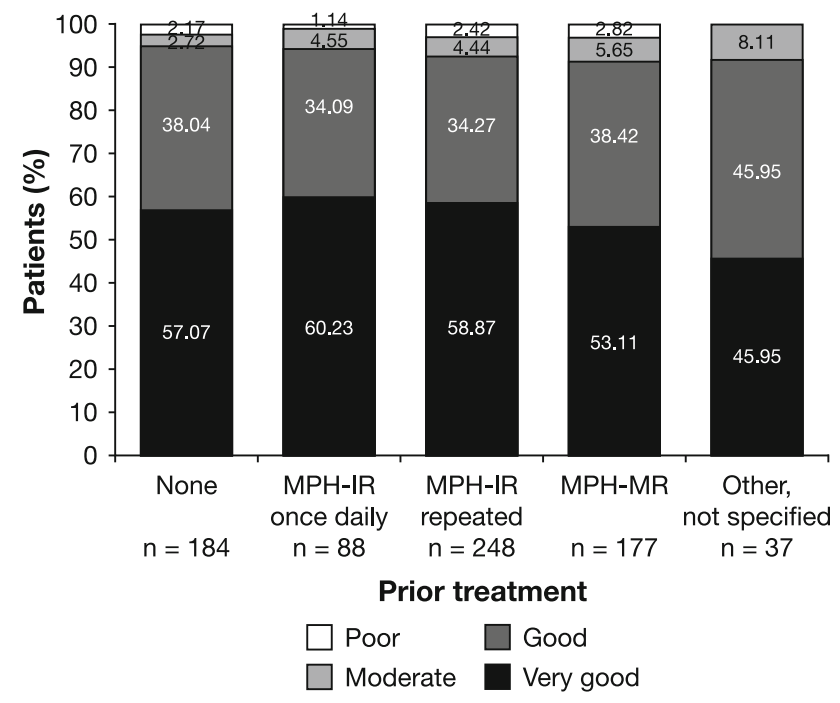

Fig. 3 Physician-rated global assessment of tolerability at Visit 3, by prior treatment. $n=734 ; 88$ missing values. $I R$ immediate release, $M P H$ methylphenidate, $M R$ modified release

tolerability of Equasym $\mathrm{XL}^{\circledR}$ differed under routine care conditions compared with the clinical trial setting.

In line with the emerging evidence showing that QoL improves with effective treatment [14], parents scored total QoL as $13.3 \%$ higher and patient-reported total QoL scores were $10.8 \%$ higher during Equasym $\mathrm{XL}^{\circledR}$ treatment compared with before starting Equasym $\mathrm{XL}^{\circledR}$. On both parents' and patients' ratings, QoL improvements during the study were greatest for the subgroup of patients who had not received any prior treatment. Due to the potential for discrepancies between parent and child reports, with parents tending to rate their children with ADHD as having lower QoL than the children themselves [14], it is generally recommended that both perspectives are assessed to provide a comprehensive assessment [10, 25]. Poor parentchild agreement in health-related QoL was reported in a recent study [30], but another study showed improvement in QoL in both children and their families, following a change in MR formulation [6]. Our observations appear to show a good concordance between patients and their parents in terms of QoL and satisfaction outcomes, which were rated as improved to a similar extent by both groups (although statistical testing was not performed).

There is a general lack of consistency across studies in the instruments that have been used to measure QoL, which, together with variability in how QoL is defined, makes cross-study, and cross-disease, comparisons difficult [14]. However, the BELLA study also used the KINDL questionnaire to assess QoL [32]. In that study, the mean (SD) KINDL total score was 76.3 (10.1), as rated by parents of children aged 7-17 years, and 73.0 (10.2) from selfratings of children and adolescents aged 11-17 years [32]. Comparison of OBSEER data (Table 2) with this reference 
population showed that overall QoL approached normative values after treatment with Equasym $\mathrm{XL}^{\circledR}$, although it should be noted that this effect was not consistently seen across all subscales, and that age groupings are not directly comparable between the two studies.

According to physicians' assessments, the tolerability of treatment was rated 'very good' or 'good' in $93.3 \%$ of the patients. Furthermore, both patients and their parents rated therapy with Equasym $\mathrm{XL}^{\circledR}$ as better than the previous drug therapy. Specific reasons for this preference were not investigated; however, it could be hypothesised that a positive clinical response would increase the likelihood of overall patient satisfaction with study treatment. Indeed, adherence generally decreases when there is a limited improvement in symptoms, or if adverse events occur [8].

Increased satisfaction should also have a positive impact on adherence to therapy. In this study, adherence was generally rated by physicians as 'very good' or 'good', and was frequently rated as better than during prior treatment, particularly for patients who had received MPH-IR dosed several times per day. This supports previous studies showing improved adherence with once-daily formulations versus multiple daily doses of IR formulations [29]. Improved adherence may result from Equasym $\mathrm{XL}^{\circledR}$ meeting patient's daily needs better than conventional MPH preparations, because of factors such as its particular pharmacokinetic profile [3] or greater ease of administration. Although adherence was rated subjectively by the physician only, the results of the OBSEER study should be an accurate reflection of the real-life situation compared with controlled study populations in which adherence is thought to be artificially high [1]. The long-term consequences of medication non-adherence have not been examined in ADHD, but it is generally believed that maintaining good adherence to treatment regimens will maximise efficacy outcomes. In a review of clinical trial populations of both children and adults, mean non-adherence rates of between 13.2 and $64 \%$ were found [1]. The highest $(64 \%)$ of these rates was seen 5 years after treatment began, suggesting that non-adherence increases when patients are followed for longer periods of time [9].

While the study design based on the routine care setting is of clear value to clinical practice, as confirmed by previous 'real-life' studies in ADHD [19, 33], there were several limitations to this study. As this was a non-randomised, open-label trial without a control group, the raters were not blinded to study treatment or dose. Patients with low QoL on prior medications may be over-represented, as this may have been a motivating factor for study participation, and this may limit the generalisability of the results. In addition, KINDL data are only available for patients aged from 8 years onwards, and not from age 6 years as originally planned.
This study demonstrated that, compared with prior therapy including MPH-MR preparations, once-daily Equasym XL ${ }^{\circledR}$ improves QoL and treatment satisfaction, as assessed by both parents and patients under routine care conditions. ADHD has a major impact on patient QoL, and using treatment options that are accepted by patients may represent an effective strategy to improve QoL. Such observational studies should prompt the further investigation of the benefits of using drug treatment in terms of QoL for patients and their families, and treatment satisfaction in a real-life setting.

Acknowledgments The authors take full responsibility for the content of the paper but thank Joanna Wright, DPhil and Jackie Marchington, PhD (Caudex Medical, Oxford, UK, supported by Shire Development Inc.) for their assistance in preparing the outline and initial draft of the manuscript, including drawing figures and tables, and collating the comments of authors and other named contributors. We would also like to thank Christine Eksteen, BPharm (Hons), Amina Elsner, MD, Monica Shaw, MD, Jonathan Smith, MSc, and Alisa Woods, PhD (all Shire Pharmaceuticals Ltd./Shire Development Inc./Shire AG at the time of review) for constructive review. The OBSEER study was funded by UCB. Additional statistical analyses and the preparation of the manuscript were supported by Shire Development Inc.

Conflict of interest Aribert Rothenberger has acted as a consultant or on advisory boards and/or as a speaker for Lilly, Shire Pharmaceuticals Ltd, Medice, Novartis and UCB. He has received research support from Shire Pharmaceuticals Ltd, the German Research Society and Schwaabe, and travel and educational grants from Shire Pharmaceuticals Ltd. Andreas Becker has nothing to disclose. Dieter Breuer has been a consultant for Lilly, Shire Pharmaceuticals Ltd, UCB and Medice. Manfred Döpfner has received research grants and/ or acted as a consultant or on advisory boards for Lilly, Shire Pharmaceuticals Ltd., Medice and Vifor.

This article is part of a supplement sponsored by Shire Development Inc.

Open Access This article is distributed under the terms of the Creative Commons Attribution Noncommercial License which permits any noncommercial use, distribution, and reproduction in any medium, provided the original author(s) and source are credited.

\section{References}

1. Adler LD, Nierenberg AA (2010) Review of medication adherence in children and adults with ADHD. Postgrad Med 122:184-191

2. American Psychiatric Association (2000) Attention-deficit and disruptive behavior disorders. Attention-deficit/hyperactivity disorder. Diagnostic and statistical manual of mental disorders, Fourth edn. American Psychiatric Association, Arlington, 85-103

3. Anderson VR, Keating GM (2006) Methylphenidate controlleddelivery capsules (Equasym ${ }^{\mathrm{TM}} \mathrm{XL}$, Metadate $\mathrm{CD}^{\mathrm{TM}}$ ): a review of its use in the treatment of children and adolescents with attentiondeficit hyperactivity disorder. Paediatr Drugs 8:319-333

4. Buitelaar J, Medori R (2010) Treating attention-deficit/hyperactivity disorder beyond symptom control alone in children and adolescents: a review of the potential benefits of long-acting stimulants. Eur Child Adolesc Psychiatry 19:325-340 
5. Bukstein OG (2004) Satisfaction with treatment for attentiondeficit/hyperactivity disorder. Am J Manag Care 10:S107-S116

6. Bukstein OG, Arnold LE, Landgraf JM, Hodgkins P (2009) Does switching from oral extended-release methylphenidate to the methylphenidate transdermal system affect health-related qualityof-life and medication satisfaction for children with attentiondeficit/hyperactivity disorder? Child Adolesc Psychiatry Ment Health 3:39

7. Cannon M, Pelham WH, Sallee FR, Palumbo DR, Bukstein O, Daviss WB (2009) Effects of clonidine and methylphenidate on family quality of life in attention-deficit/hyperactivity disorder. J Child Adolesc Psychopharmacol 19:511-517

8. Chacko A, Newcorn JH, Feirsen N, Uderman JZ (2010) Improving medication adherence in chronic pediatric health conditions: a focus on ADHD in youth. Curr Pharm Des $16: 2416-2423$

9. Charach A, Ickowicz A, Schachar R (2004) Stimulant treatment over five years: adherence, effectiveness, and adverse effects. J Am Acad Child Adolesc Psychiatry 43:559-567

10. Coghill D (2010) The impact of medications on quality of life in attention-deficit hyperactivity disorder: a systematic review. CNS Drugs 24:843-866

11. Coghill D, Danckaerts M, Sonuga-Barke E, Sergeant J (2009) Practitioner review: quality of life in child mental health-conceptual challenges and practical choices. J Child Psychol Psychiatry 50:544-561

12. Coghill D, Soutullo C, d'Aubuisson C, Preuss U, Lindback T, Silverberg M, Buitelaar J (2008) Impact of attention-deficit/ hyperactivity disorder on the patient and family: results from a European survey. Child Adolesc Psychiatry Ment Health 2:31

13. Cohen J (1988) Statistical power analysis for the behavioural sciences. Lawrence Erlbaum Associates, Hillsdale

14. Danckaerts M, Sonuga-Barke EJ, Banaschewski T, Buitelaar J, Dopfner M, Hollis C, Santosh P, Rothenberger A, Sergeant J, Steinhausen HC, Taylor E, Zuddas A, Coghill D (2010) The quality of life of children with attention deficit/hyperactivity disorder: a systematic review. Eur Child Adolesc Psychiatry 19:83-105

15. Döpfner M, Görtz-Dorten A, Breuer D, Rothenberger A (2011) An observational study of once-daily modified-release methylphenidate in ADHD: effectiveness on symptoms and impairment, and safety. Eur Child Adolesc Psychiatry. doi:10.1007/s00787011-0202-4

16. Efron D, Jarman FC, Barker MJ (1998) Child and parent perceptions of stimulant medication treatment in attention deficit hyperactivity disorder. J Paediatr Child Health 34:288-292

17. Escobar R, Soutullo CA, Hervas A, Gastaminza X, Polavieja P, Gilaberte I (2005) Worse quality of life for children with newly diagnosed attention-deficit/hyperactivity disorder, compared with asthmatic and healthy children. Pediatrics 116:e364-e369

18. Frazier TW, Weiss M, Hodgkins P, Manos MJ, Landgraf JM, Gibbins C (2010) Time course and predictors of health-related quality of life improvement and medication satisfaction in children diagnosed with attention-deficit/hyperactivity disorder treated with the methylphenidate transdermal system. J Child Adolesc Psychopharmacol 20:355-364

19. Goetz M, Yeh CB, Ondrejka I, Akay A, Herczeg I, Dobrescu I, Kim BN, Jin X, Riley AW, Martenyi F, Harrison G, Treuer T (2010) A 12-month prospective, observational study of treatment regimen and quality of life associated with ADHD in Central and Eastern Europe and Eastern Asia. J Atten Disord. doi: $10.1177 / 1087054710381480$

20. Görtz-Dorten A, Breuer D, Hautmann C, Rothenberger A, Döpfner M (2011) What contributes to patient and parent satisfaction with medication in the treatment of children with ADHD?
A report on the development of a new rating scale. Eur Child Adolesc Psychiatry. doi:10.1007/s00787-011-0207-z

21. Gurkan K, Bilgic A, Turkoglu S, Kilic BG, Aysev A, Uslu R (2009) Depression, anxiety and obsessive-compulsive symptoms and quality of life in children with attention-deficit hyperactivity disorder (ADHD) during three-month methylphenidate treatment. J Psychopharmacol 24:1810-1818

22. Hankin CS, Wright A, Gephart H (2001) The burden of attention deficit/hyperactivity disorder. Drug Benefit Trends 13:7-14

23. Horrigan JP, Kohli RR (2002) The impact of dosing frequency on psychostimulant compliance in ADHD. NIMH-42nd Annual NCDEU Meeting Poster 56

24. Klassen AF, Miller A, Fine S (2004) Health-related quality of life in children and adolescents who have a diagnosis of attentiondeficit/hyperactivity disorder. Pediatrics 114:e541-e547

25. Klassen AF, Miller A, Fine S (2006) Agreement between parent and child report of quality of life in children with attention-deficit/hyperactivity disorder. Child Care Health Dev 32:397-406

26. Kollins SH (2007) Measuring quality of life in children with ADHD. Medscape Psychiatry Mental Health http://cme.medscape. com/viewarticle/562652_print. Accessed 18 Nov 2010

27. Manos M, Frazier TW, Landgraf JM, Weiss M, Hodgkins $P$ (2009) HRQL and medication satisfaction in children with ADHD treated with the methylphenidate transdermal system. Curr Med Res Opin 25:3001-3010

28. Morris SB (2008) Estimating effect sizes from pretest-posttestcontrol group designs. Organ Res Methods 11:364-386

29. MTA Cooperative Group (2004) National Institute of Mental Health multimodal treatment study of ADHD follow-up: changes in effectiveness and growth after the end of treatment. Pediatrics 113:762-769

30. Rajmil L, Estrada MD, Herdman M, Serra-Sutton V, Tebe C, Izaguirre J, Alda JA, Alonso J, Riley AW, Forrest CB, Starfield B (2009) Parent-child agreement in the health related quality of life (HRQOL) of children with attention-deficit/hyperactivity disorder (ADHD): a longitudinal study. An Pediatr (Barc) 70:553-561

31. Ravens-Sieberer U, Bullinger M (1998) Assessing health-related quality of life in chronically ill children with the German KINDL: first psychometric and content analytical results. Qual Life Res 7:399-407

32. Ravens-Sieberer U, Erhart M, Wille N, Bullinger M (2008) Health-related quality of life in children and adolescents in Germany: results of the BELLA study. Eur Child Adolesc Psychiatry 17(Suppl 1):148-156

33. Remschmidt H, Hoare P, Ettrich C, Rothenberger A, Santosh P, Schmidt M, Spender Q, Tamhne R, Thompson M, Tinline C, Trott GE, Medori R (2005) Symptom control in children and adolescents with attention-deficit/hyperactivity disorder on switching from immediate-release MPH to OROS MPH results of a 3-week open-label study. Eur Child Adolesc Psychiatry 14:297-304

34. Riley AW, Coghill D, Forrest CB, Lorenzo MJ, Ralston SJ, Spiel G (2006) Validity of the health-related quality of life assessment in the ADORE study: Parent Report Form of the CHIP-Child Edition. Eur Child Adolesc Psychiatry 15(Suppl 1):I63-I71

35. Riley AW, Spiel G, Coghill D, Dopfner M, Falissard B, Lorenzo MJ, Preuss U, Ralston SJ (2006) Factors related to health-related quality of life (HRQoL) among children with ADHD in Europe at entry into treatment. Eur Child Adolesc Psychiatry 15(Suppl 1):I38-I45

36. Rosnow RL, Rosenthal R (2009) Effect sizes: why, when and how to use them. J Psychol 217:6-14

37. Saylor K, Buermeyer C, Sutton V, Faries D, Khan S, Schuh K (2007) The Life Participation Scale for attention-deficit/hyperactivity disorder-child version: psychometric properties of an 
adaptive change instrument. J Child Adolesc Psychopharmacol 17:831-842

38. Varni JW, Burwinkle TM (2006) The PedsQL as a patientreported outcome in children and adolescents with attentiondeficit/hyperactivity disorder: a population-based study. Health Qual Life Outcomes 4:26

39. Wehmeier PM, Schacht A, Dittmann RW, Dopfner M (2008) Global impression of perceived difficulties in children and adolescents with attention-deficit/hyperactivity disorder: reliability and validity of a new instrument assessing perceived difficulties from a patient, parent and physician perspective over the day. Child Adolesc Psychiatry Ment Health 2:10

40. World Health Organization (1992) International Classification of Diseases (ICD-10), 10th edn. World Health Organization, Geneva 